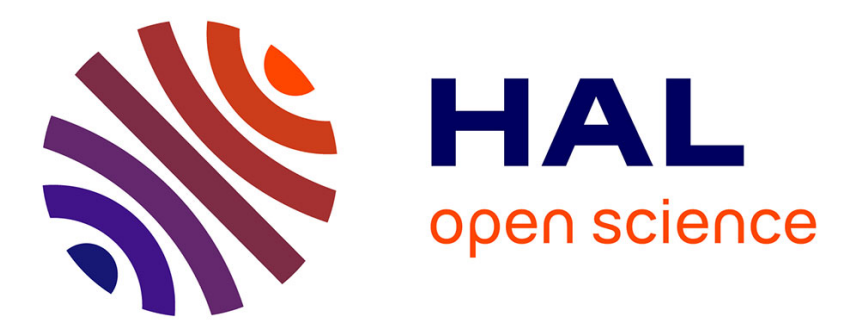

\title{
A simple transferable adaptive potential to study phase separation in large-scale $\mathrm{xMgO}-(1-\mathrm{x}) \mathrm{SiO} 2$ binary glasses
}

Xavier Bidault, Stéphane Chaussedent, Wilfried Blanc

\section{To cite this version:}

Xavier Bidault, Stéphane Chaussedent, Wilfried Blanc. A simple transferable adaptive potential to study phase separation in large-scale xMgO-(1-x)SiO 2 binary glasses. Journal of Chemical Physics, 2015, 143, pp.154501. hal-01233738

\section{HAL Id: hal-01233738 \\ https://hal.science/hal-01233738}

Submitted on 26 Nov 2015

HAL is a multi-disciplinary open access archive for the deposit and dissemination of scientific research documents, whether they are published or not. The documents may come from teaching and research institutions in France or abroad, or from public or private research centers.
L'archive ouverte pluridisciplinaire HAL, est destinée au dépôt et à la diffusion de documents scientifiques de niveau recherche, publiés ou non, émanant des établissements d'enseignement et de recherche français ou étrangers, des laboratoires publics ou privés. 


\title{
A simple transferable adaptive potential to study phase separation in large-scale xMgO-(1-x) $\mathrm{SiO}_{2}$ binary glasses
}

\author{
Xavier Bidault ${ }^{1, a}$, Stéphane Chaussedent ${ }^{1}$, Wilfried Blanc ${ }^{2}$ \\ ${ }^{1}$ Université d'Angers, Laboratoire de Photonique d'Angers (LPhiA) - UPRES EA 4464, 2 Bd \\ Lavoisier, 49045 ANGERS Cedex 01, France \\ ${ }^{2}$ Université de Nice-Sophia Antipolis, CNRS, Laboratoire de Physique de la Matière Condensée \\ (LPMC) - UMR 7336, Parc Valrose, 06100 NICE Cedex 2, France
}

\begin{abstract}
A simple transferable adaptive model is developed and it allows for the first time to simulate by Molecular Dynamics the separation of large phases in the $\mathrm{MgO}-\mathrm{SiO}_{2}$ binary system, as experimentally observed and as predicted by the phase diagram, meaning that separated phases have various compositions. This is a real improvement over fixed-charge models, which are often limited to an interpretation involving the formation of pure clusters, or involving the Modified Random Network model. Our adaptive model, efficient to reproduce known crystalline and glassy structures, allows us to track the formation of large amorphous $\mathrm{Mg}$-rich Si-poor nanoparticles in an Mg-poor Si-rich matrix from a $0.1 \mathrm{MgO}-0.9 \mathrm{SiO} \mathrm{melt}_{2}$
\end{abstract}

\section{INTRODUCTION}

Phase separation in binary silicate glasses is a widespread phenomenon. Many experimental data concerning numerous binary systems have been compiled by Hudon et al. ${ }^{1}$. Some Molecular Dynamics (MD) studies give an insight of the conditions leading to this phase separation ${ }^{2,3}$, but they are often limited to an $\mathrm{AB}$ mixture that separates into pure phases A and B. Even in the case of silica-based glasses, these simulations show the trend for added ions to segregate and to form clusters $\left(\mathrm{Ca}^{2+}, \mathrm{Mg}^{2+}, \mathrm{Li}^{+}, \mathrm{Er}^{3+}\right.$, and $\mathrm{Eu}^{3+}$, in Ref. 4, 5, 6, 7 and 8, respectively, and a comparison of $\mathrm{Li}^{+}, \mathrm{Na}^{+}$and $\mathrm{K}^{+}$in Ref. 9). This behavior is consistent with the Modified Random Network (MRN) model proposed by Greaves ${ }^{10}$, where channels of modifying components are experimentally evidenced, explaining for instance the easier diffusion of $\mathrm{Na}^{+}$ions in $\mathrm{Na}_{2} \mathrm{O}-\mathrm{SiO}_{2}$ binary glass. The existence of $\mathrm{Ca}-\mathrm{O}-\mathrm{Ca}$ and $\mathrm{Mg}-\mathrm{O}-\mathrm{Mg}$ bridges has also been evidenced in $\mathrm{CaO}-$ $\mathrm{SiO}_{2}{ }^{11}$ and $\mathrm{MgO}-\mathrm{SiO}_{2}{ }^{12}$ binary glasses, and confirmed by means of MD simulations ${ }^{4,5}$. However, at a larger scale, the study of a phase diagram like the one of the $\mathrm{MgO}-\mathrm{SiO}_{2}$ system $^{13}$ shows that the separated phases are not as simple as pure $\mathrm{MgO}$ ones separated from pure $\mathrm{SiO}_{2}$ others. On the contrary, it predicts under a certain temperature the coexistence of two liquid phases, both composed of different proportions of $\mathrm{MgO}$ and $\mathrm{SiO}_{2}$ : an $\mathrm{Mg}$-rich $\mathrm{Si}$-poor one and a $\mathrm{Si}$-rich $\mathrm{Mg}$ poor other one. The quench of this mixture can lead to a spinodal decomposition, with tangled channels of both phases, or the formation of disjoint areas of one of the phases in a matrix of the other one. This phase separation mechanism is

\footnotetext{
${ }^{\text {a }}$ Electronic mail: xavier.bidault@univ-angers.fr
} 
exploited by Blanc et al. ${ }^{14}$ to form nanoparticles (NP), grown in situ within a material composed of, among other compounds, $\mathrm{MgO}$ and $\mathrm{SiO}_{2}$. Resulting NP have been analyzed by Secondary Ion Mass Spectroscopy (SIMS) and are found to correspond to Mg-rich Si-poor phases. This composition trend has been confirmed very recently by a sharper analysis using Atom Probe Tomography (ATP) ${ }^{15}$.

Up to now, no MD simulation has been able to reproduce the formation of such NP in $x \mathrm{MgO}-(1-\mathrm{x}) \mathrm{SiO}_{2}$ binary glasses, by using the phase separation phenomenon occurring for $\mathrm{x}<0.4$, within the stable immiscibility gap ${ }^{13}$. No MD study reports the formation of NP of the size obtained in the present paper (a few tens of $\AA$ ). Phase separation involves cation-Oxygen bonds that are more or less covalent, whose Oxygen are more or less polarized, which more or less screen the surrounded cation ${ }^{1}$. Consequently, a fixed-charge model seems to be inefficient to accurately simulate the separation of complex phases. One needs to take into account the different ionicity (or covalency) of metal-Oxygen bonds, as well as the electrostatic environment of each ion according to its neighbors. Therefore, a variable-charge model is required. Such a reactive potential, like $\operatorname{ReaxFF}^{16}$ or $\mathrm{COMB}^{17}$, is built around a self-consistent charge equilibration scheme and bond order concept. It is suitable to simulate multi-component multi-functional systems like an interface between a bulk oxide and a bulk metal, but the drawback of its complexity is an increased computational cost. Glassy materials studied in this paper are ionic bulk materials and there is no metal/oxide interface. Hence, a simpler adaptive model is proposed and developed in this context. This model has to: (a) take into account the different ionicity of the metal-Oxygen bonds; (b) be composition dependent, like, for instance, the one used by Kieu et al. for sodium borosilicate glass systems ${ }^{18}$; (c) dynamically and locally adapt, like the one used by Huang et al. to study borate glass anomalies ${ }^{19}$; (d) be as simple as possible to perform long-time simulations on large-scale systems; (e) be easily transposable to any silica-based systems.

After a description of this simple adaptive potential, its accuracy and its transferability (i.e. its ability to explore the whole $\mathrm{MgO}-\mathrm{SiO}_{2}$ phase diagram with a unique parameter set) are tested on known experimental crystalline and glassy structures of various compositions. Then, the effects of the composition of the binary system and the impact of the quench rate on phase separation are studied. Finally, the efficiency of this adaptive potential to reproduce the phase separation is used to track the formation of $\mathrm{NP}$ in a $0.1 \mathrm{MgO}-0.9 \mathrm{SiO}_{2}$ binary glass.

\section{DEVELOPMENT OF THE POTENTIAL}

In the model developed hereinafter, designed for ionic bulk materials, cations are assumed to present fixed partial charges. The transferability is assured by the reactive adaptation of each Oxygen charge to its local cationic environment. 


\section{A. Taking into account the more ionic character of $\mathrm{Mg}-\mathrm{O}$ bond \\ 1. Determination of $\mathrm{Mg}$ charge}

Using the assumption of fixed cation charges, setting the partial charge of $\mathrm{Mg}^{2+}$ to the half of the $\mathrm{Si}^{4+}$ one is not relevant with the fact that the $\mathrm{Mg}-\mathrm{O}$ bond is more ionic than the $\mathrm{Si}-\mathrm{O}$ one. Indeed, based on a comparative ab initio study of $\mathrm{MgO}$ and $\mathrm{SiO}_{2}{ }^{20}$, a polarizable force field parameterization sets $\mathrm{Mg}$ charge at $+1.23 \mathrm{e}$ and $\mathrm{Si}$ one at $+1.86 \mathrm{e}$. The resulting ratio is clearly not equal to half. Based on some other ab initio studies of $\mathrm{MgO}^{21,22}, \mathrm{Mg}-\mathrm{O}$ bond is expected to have a more ionic character than $\mathrm{Si}-\mathrm{O}$ one in binary silicate glasses. To estimate the new partial charge carried by $\mathrm{Mg}$ ions, the Rappe \& Goddard electronegativity equalization method $(\mathrm{QEq})^{23}$ is used, as implemented in GULP package (General Utility Lattice Program) ${ }^{24,25}$, but with a constraint for mean Si charge to be equal to $+2.4 \mathrm{e}$ (the choice of this value is explained in the next paragraph). Performed on the primitive cell of an $\mathrm{MgSiO}_{3}$ enstatite structure, resulting partial charges of each ion are reported in the TABLE I. The two Mg sites and the two Si sites show a very small charge deviation to the mean, with, at the maximum, $\pm 1.2 \%$ around $+1.3254 \mathrm{e}$ and $\pm 0.3 \%$ around +2.4000 e, respectively. In contrast, the charge distribution of the six Oxygen sites is broader, with a maximum of $\pm 6.7 \%$ around $-1.2418 \mathrm{e}$. Consequently, only cation charges are fixed in our model: the Si partial charge is set at $+2.40 \mathrm{e}$, and the $\mathrm{Mg}$ one is rounded and set at $+1.33 \mathrm{e}$ for the rest of this study.

TABLE I. GULP partial charge of each atom in primitive cell of $\mathrm{MgSiO}_{3}$ enstatite structure

\begin{tabular}{lccc}
\hline \hline & $\mathrm{Mg}$ & $\mathrm{Si}$ & $\mathrm{O}$ \\
\hline & 1.3414 & 2.3924 & -1.1584 \\
& 1.3094 & 2.4076 & -1.1677 \\
Partial charge & & & -1.2416 \\
& & & -1.2612 \\
& & & -1.3078 \\
& & & -1.3139 \\
\hline Mean charge & 1.3254 & 2.4000 & -1.2418 \\
Deviation to mean charge & $1.2 \%$ & $0.3 \%$ & $6.7 \%$ \\
\hline \hline
\end{tabular}

\section{Parameterization of $\mathrm{Mg}-\mathrm{O}$ interaction}

Many fixed-charge potentials for $\mathrm{SiO}_{2}$ are available in the literature and accurately reproduce various properties of silica polymorphs. Among them, the one developed by Pedone $e t$ al. $^{26}$ is particularly efficient to reproduce structural and mechanical properties of silica crystals and glasses. This potential is composed of three terms: a long-range Coulomb interaction, a short-range Morse function and a repulsive contribution $C / r^{12}$. The complete expression is given by:

$$
U(r)=\frac{q_{i} q_{j}}{r}+D_{i j}\left[\left\{1-e^{-a_{i j}\left(r-r_{0}\right)}\right\}^{2}-1\right]+\frac{C_{i j}}{r^{12}}
$$


where $i$ and $j$ are atom types, $q_{i}$ and $q_{j}$ are partial charges, $D_{i j}, a_{i j}, r_{0}$ and $C_{i j}$ are adjustable parameters, and $r$ the interatomic distance. For this potential, the $\mathrm{Si}$ partial charge is set at $+2.40 \mathrm{e}$, which corresponds to the constraint added in GULP, as seen in the previous paragraph. This allows keeping on using this potential for silica-based compounds. New parameters for $\mathrm{Mg}-\mathrm{O}$ interaction are derived from the method described by Pedone et al. in their study ${ }^{26}$, using the free energy minimization implemented in GULP package, performed on the crystalline structure of MgO periclase. Usually, regardless of the oxide that is modeled, a common approximation is to use the Morse parameters of the O-O interaction determined in $\mathrm{SiO}_{2}$. The new charge $\mathrm{q}_{\mathrm{Mg}}=+1.33 \mathrm{e}$ determined in the above paragraph is used, inducing the physical choice of $\mathrm{q}_{\mathrm{O}}=-1.33 \mathrm{e}$ in order to respect the electroneutrality. This yields the new Mg-O parameters, reported in TABLE II, which perfectly reproduce the periclase structural and elastic properties used for the fit: rock-salt structure with cubic lattice parameter $4.217 \AA$, elastic constants $\mathrm{C}_{11}=294 \mathrm{GPa}$ and $\mathrm{C}_{12}=93 \mathrm{GPa}$.

TABLE II. Potential parameters (bold : new Mg-O interaction parameters; italic : parameters from Pedone et al. ${ }^{26}$ )

\begin{tabular}{lcccc}
\hline \hline & $D_{i j}(\mathrm{eV})$ & $a_{i j}\left(\AA^{-1}\right)$ & $r_{0}(\AA)$ & $C_{i j}\left(\mathrm{eV} . \AA^{12}\right)$ \\
\hline $\mathrm{Si}^{2.4}-\mathrm{Si}^{2.4}$ & - & - & - & 1.0 \\
$\mathrm{Si}^{2.4}-\mathrm{O}^{-1.2}$ & 0.340554 & 2.006700 & 2.100000 & - \\
$\mathrm{Mg}^{1.33}-\mathrm{Mg}^{1.33}$ & - & - & - & - \\
$\mathrm{Mg}^{1.33}-\mathrm{Si}^{2.4}$ & - & - & - & $\mathbf{1 . 0}$ \\
$\mathrm{Mg}^{1.33}-\mathbf{O}^{-1.33}$ & $\mathbf{0 . 2 0 9 2 9 0}$ & $\mathbf{1 . 3 7 6 8 7 1}$ & $\mathbf{2 . 7 3 3 0 4 1}$ & 22.0 \\
$\mathrm{O}^{\mathrm{q}}-\mathrm{O}^{\mathrm{q}}$ & 0.042395 & 1.379316 & 3.618701 & \\
\hline \hline
\end{tabular}

q and q' : each oxygen partial charge depends on its own cationic environment

\section{B. Global and local transferability assured by reactive partial charges of Oxygen atoms}

In order to respect the electroneutrality of the binary system, the negative partial charge of Oxygen atoms is adapted to compensate the positive charge of both cations composing the $\mathrm{xMgO}-(1-\mathrm{x}) \mathrm{SiO}_{2}$ mixing. This yields a value that depends on the $\mathrm{MgO}$ fraction $\mathrm{x}$, and therefore the model is not yet transferable when changing the proportions of each oxide. To assure transferability and to explore the whole phase diagram by means of a unique model, a computational method that allows each Oxygen charge to dynamically react to its own cationic environment is designed. The charge of each Oxygen atom is equal to a negative weighted sum of the cationic charges surrounding it. All positive charges within a sphere of radius $r_{c u t}$ around a central Oxygen are multiplied by a weighting function $f(r)$, decreasing with $r$, where $r$ is the distance between a cation and this central Oxygen atom. Then, all Oxygen atoms within the same radius $r_{c u t}$ are counted and weighted by the same function $f(r)$, where $r$ is now the distance between an Oxygen atom and the central Oxygen. The resulting charge of the central Oxygen is equal to the ratio of the negative weighted sum of positive charges to the weighted count of Oxygen atoms, as summarized in equation (2). The weighting function $f(r)$ has the empirical form proposed in equation (3). Finally, to remove possible statistical bias, all Oxygen charges are scaled so that the mean value is equal to the mean Oxygen charge imposed by electroneutrality. The cutoff radius $r_{c u t}$ of the weighting function $f(r)$ is empirically set at $7.5 \AA$. This value has been chosen so that the short- and medium-range 
structure of pure silica glass is unchanged when compared to the non-adaptive Pedone potential. With the chosen form of $f(r)$, this $r_{c u t}$ distance is long enough to include the first coordination sphere with a weighting factor near unity, and it is short enough to evidence local variations of the cationic environment.

$$
\begin{gathered}
q_{\text {oxygen }}=-\sum_{\substack{\text { cations } \\
r<r_{\text {cut }}}} f(r) \cdot q_{\text {cation }} / \sum_{\substack{\text { oxygen atoms } \\
r<r_{\text {cut }}}} f(r) \\
f(r)=\frac{1}{2}\left\{1+\cos \left(\frac{\pi r}{r_{\text {cut }}}\right)\right\} \approx 2\left(\frac{r}{r_{\text {cut }}}\right)^{3}-3\left(\frac{r}{r_{\text {cut }}}\right)^{2}+1
\end{gathered}
$$

Nevertheless, the use of these individual charges in cation-Oxygen attractions would need the short-range part (the Morse function) of our potential to be also charge-dependent. For instance, concerning Si-O bond in Mg-enstatite, the corresponding Morse part is parameterized for $\mathrm{Si}^{2.4}-\mathrm{O}^{-1.2}$. But with the presence of $\mathrm{Mg}^{1.33}$ atoms, Oxygen mean charge becomes lower than -1.2e. This results in a stronger $\mathrm{Si}-\mathrm{O}$ electrostatic attraction that should be balanced by an adequate stronger Morse repulsion to keep on fitting the experimental distance. To keep things simple for cation-Oxygen interactions, we do the approximation to keep the Oxygen partial charge and Morse parameters as fitted in their pure respective materials. This means that the only interactions that adapt in our model (i.e. the only approximation that is not neglected or compensated) are the electrostatic parts of the Oxygen-Oxygen repulsions (q and q' in Table II).

\section{COMPUTATIONAL METHODS}

Molecular dynamics (MD) simulations are carried out by a modified version of LAMMPS ${ }^{27}$ (Large-scale Atomic/Molecular Massively Parallel Simulator), with periodic boundary conditions (PBC). LAMMPS uses the velocityStörmer-Verlet algorithm to solve the equations of motion. The modification concerns the computation of Oxygen charges and the related O-O repulsions. The general scheme of each time step is: (a) new atomic positions are computed from positions, velocities and forces of the previous time step; (b) new Oxygen charges are computed from new positions; (c) new forces are calculated from new positions and new Oxygen charges; (d) new velocities are computed from new forces, and velocities and forces of the previous time step.

The long-range Coulomb term is evaluated using the Wolf method $^{28}$, consisting in a spherically-truncated, charge-neutralized, shifted, pairwise $1 / r$ summation. Thus, the following replacement is made in Eq. (1):

$$
\frac{q_{i} q_{j}}{r} \rightarrow \frac{q_{i} q_{j}}{r} \operatorname{erfc}(\alpha r)-\lim _{r \rightarrow R_{c}}\left\{\frac{q_{i} q_{j}}{r} \operatorname{erfc}(\alpha r)\right\}
$$


where $\alpha$ is the damping parameter and $R_{c}$ the long-range cutoff. This method, initially developed for ionic crystals and melts, gives good results for amorphous materials like silica ${ }^{29,30}$ and silica-based ${ }^{31}$ glasses. It also well reproduces the energetics and the dynamics of various typical systems ${ }^{32}$. The main advantages of the Wolf method are: (a) the computational cost increases linearly as $O(N)$ with system size, instead of, at best, $O\left(N^{3 / 2}\right)$ for Ewald method ( $N$ is the number of atoms involved in the simulation); (b) the inherent periodicity of the Ewald sum is no more imposed to the system. For this study, the short-range cutoff is set at $5.5 \AA$. Considering both the total energy and the short- and medium-range structure obtained from melt/quench sequences of a pure $\mathrm{SiO}_{2}$ system, the couple of values $\alpha=0.30 \AA^{-1}$ and $R_{c}=7.5 \AA$ is chosen among the tested ones giving the best match between Wolf and Ewald summations. Unless otherwise indicated, the simulations are made at constant atmospheric pressure ( $\mathrm{P}=1$ bar), using the Nosé-Hoover NPT algorithm (constant Number of atoms, controlled Pressure and Temperature) with damping parameters of 0.010 ps for temperature control and 0.100 ps for pressure control, and a time step of $1 \mathrm{fs}$. Each Oxygen charge is adapted to its own environment at each time step, as explained in the previous paragraph.

\section{RESULTS AND DISCUSSION}

Some known crystalline and glassy structures of various compositions are modeled with this new effective potential, and they are compared to experimental data. After this assessment, we study its ability to reproduce the phase separation phenomenon as it occurs in $\mathrm{xMgO}-(1-\mathrm{x}) \mathrm{SiO}_{2}$ binary glasses. Finally, we track the formation of nanoparticles (NP) during the slow quench of a $0.1 \mathrm{MgO}-0.9 \mathrm{SiO}_{2}$ melt, and the mean composition of these $\mathrm{NP}$ is analyzed.

\section{A. Crystal and glass densities}

To assess the transferability of this new reactive potential, we report in TABLE III the computed densities of some known $\mathrm{xMgO}-(1-\mathrm{x}) \mathrm{SiO}_{2}$ crystalline structures: $\mathrm{Mg}$-enstatite $(\mathrm{x}=0.50), \mathrm{Mg}$-forsterite $(\mathrm{x}=0.67)$ and $\mathrm{MgO}$ periclase $(\mathrm{x}=1.00)$, obtained after a 40-ps NPT stage at $300 \mathrm{~K}$ and 1 bar. The deviations to experimental densities are below $5 \%$. Pair correlation functions are unaltered and all experimental structures are well-preserved.

TABLE III. Density $\left(\mathrm{g} / \mathrm{cm}^{3}\right)$ of modeled crystals at $300 \mathrm{~K}$ and 1 bar

\begin{tabular}{lccc}
\hline Crystal name (xMgO) & Mg-enstatite (0.50) & Mg-forsterite (0.67) & Periclase (1.00) \\
\hline Model & 3.13 & 3.10 & 3.45 \\
Experimental & 3.20 & 3.23 & 3.57 \\
Deviation (\%) & $-2.2 \%$ & $-4.0 \%$ & $-3.4 \%$ \\
\hline \hline
\end{tabular}

Melt/quench sequences from random atomic distributions are performed to model binary glasses containing various proportions of $\mathrm{MgO}$ and $\mathrm{SiO}_{2}$. Whatever the composition, the number of $\mathrm{Si}$ atoms is constant and equal to 2916 . 
The numbers of Magnesium and Oxygen atoms added in the simulation box are adjusted according to the target composition. As explained above, the mean charge of Oxygen atoms is controlled to keep neutral the charge of the $\mathrm{xMg}{ }^{1.33} \mathrm{O}-(1-\mathrm{x}) \mathrm{Si}^{2.4} \mathrm{O}_{2}$ system. The initial random configuration is melted for $400 \mathrm{ps}$ at $4000 \mathrm{~K}$ to form an homogeneous liquid, which is then cooled down at $0.5 \mathrm{~K} / \mathrm{ps}$ (every $400 \mathrm{ps}$, the temperature is decreased by $200 \mathrm{~K}$ ), and finally kept at $300 \mathrm{~K}$ for $400 \mathrm{ps}$. Resulting densities of these glasses are reported in TABLE IV. The FIG. 1 compares computed densities with the experimental ones reported by Al-Hasni and Mountjoy ${ }^{5}$ (obtained from experimental work of Wilding et $a l .{ }^{33}$ ). Even if the densities of modeled glasses are higher than experimental known values, deviations stay below $9 \%$. In fact, this density increase is consistent with the anomalous behavior of silica glass observed by Brückner ${ }^{34}$ and Shelby ${ }^{35}$. Indeed, the slower the quench rate is, the lower the experimental density of silica glass is. MD quench rate being many orders higher than laboratory ones, it seems consistent for modeled silica-based glass to have a higher density than experimental one. This anomalous behavior of silica glass also appears in the MD simulations made by Vollmayr et al. ${ }^{36}$, using the BKS potential, and it has also been verified for the potential used in this paper. So, regardless of the high quench rate in MD, the density of modeled glass clearly displays a linear dependence with $\mathrm{MgO}$ fraction, which is confirmed by a correlation coefficient $\mathrm{R}^{2}=0.994$ close to 1 (black line in FIG. 1 ), and this, interestingly, even in the range where phase separation occurs (see paragraph IV.C). This linear behavior has been previously reported by Hanada et $a l .{ }^{37}$ for amorphous films prepared by rf-sputtering (for $\mathrm{xMgO}$ between 0.0 and 0.6 ). Such a result allows the prediction of a similar behavior for experimental glass prepared by fusion/quench technique, especially in the domain 0.0 $<\mathrm{x}_{\mathrm{MgO}}<0.5$ for which no published value is available to our knowledge. Hence, we can assume that the experimental density $\rho_{\text {exp }}$ of the xMgO-(1-x) $\mathrm{SiO}_{2}$ system is a linear function of the $\mathrm{MgO}$ fraction, given by $: \rho_{\text {exp }}\left(\mathrm{g} \cdot \mathrm{cm}^{-3}\right)=2.20+$ $1.96 \mathrm{x}_{\mathrm{MgO}}$ (dotted line in FIG. 1).

TABLE IV. Final densities $\left(\mathrm{g} / \mathrm{cm}^{3}\right)$ of modeled glasses $\mathrm{xMgO}-(1-\mathrm{x}) \mathrm{SiO}_{2}$ at $300 \mathrm{~K}$ and $1 \mathrm{bar}$

\begin{tabular}{llllllllllll}
\hline $\mathrm{xMgO}$ & 0.00 & 0.05 & 0.10 & 0.20 & 0.30 & 0.40 & 0.45 & 0.50 & 0.55 & 0.60 & 0.67 \\
\hline Model & 2.27 & 2.38 & 2.45 & 2.58 & 2.70 & 2.82 & 2.88 & 2.97 & 3.03 & 3.08 & 3.12 \\
Experimental & 2.20 & & & & & & & 2.74 & & & 2.92 \\
Deviation (\%) & $3.2 \%$ & & & & & & & $8.4 \%$ & & & $6.8 \%$ \\
\hline \hline
\end{tabular}

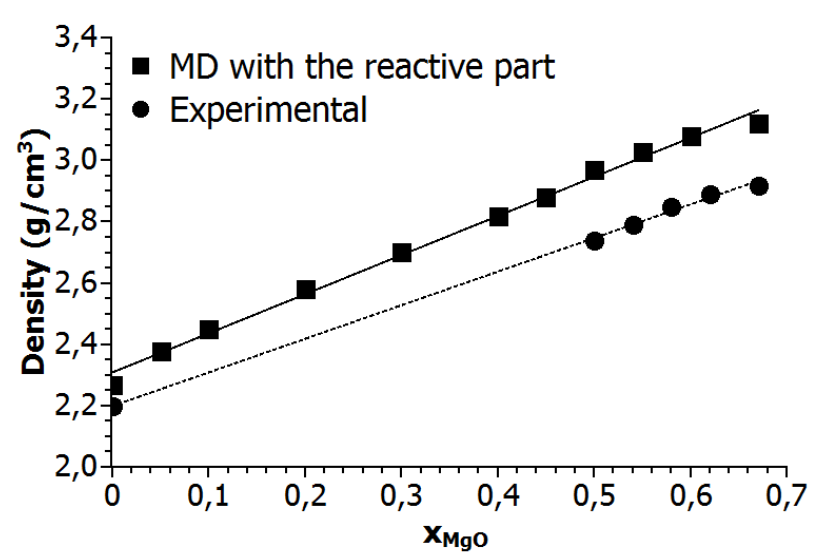

FIG. 1. Density of binary glasses $\mathrm{xMgO}-(1-\mathrm{x}) \mathrm{SiO}_{2}$; $\mathrm{MD}$ with the reactive part of the potential (squares); $\mathrm{MD}$ linear approximation (line); experimental values from Ref. 5 (circles); experimental linear extrapolation (dotted line). 


\section{B. Structure comparison with X-ray diffraction}

An additional assessment is done by comparing modeled glasses to structural data obtained from X-ray diffraction of $\mathrm{MgSiO}_{3}$ glass $(\mathrm{x}=0.50)$ and $\mathrm{Mg}_{2} \mathrm{SiO}_{4}$ glass $(\mathrm{x}=0.67)$. Experimental ${ }^{33}$ structure factor $\mathrm{S}(\mathrm{Q})$ and total correlation function $\mathrm{T}(\mathrm{r})$, as well as reconstructed-from-model ones (see Ref. 38 for the method), are displayed in FIG. $2 a$ $\& 2 c$ for $\mathrm{MgSiO}_{3}$ glass, and in FIG. $2 b \& 2 d$ for $\mathrm{Mg}_{2} \mathrm{SiO}_{4}$ glass. $\mathrm{MgSiO}_{3}$ glass and $\mathrm{Mg}_{2} \mathrm{SiO}_{4}$ glass partial distribution functions are displayed in FIG.2e and FIG.2f, respectively (RDF is for radial distribution function and CDF is for cumulated distribution function). Results obtained from our model and from experiments are in good agreement. Regarding T(r) functions (FIG. $2 c \& 2 d$ ), modeled and experimental peak positions at $1.60 \AA$ align well in both figures, as well as the ones at $2.05 \AA$ for $\mathrm{MgSiO}_{3}$ glass and at $2.07 \AA$ for $\mathrm{Mg}_{2} \mathrm{SiO}_{4}$ glass. The peak at $1.60 \AA$ corresponds to $\mathrm{Si}-\mathrm{O}$ correlation distance. The $\mathrm{Si}-\mathrm{O}$ coordination number $(\mathrm{CN})$ is 4.0 , in agreement with the geometry of the $\mathrm{SiO}_{4}$ tetrahedron, which is the structural unit of silica-based glasses. Interestingly, the proposed reactive O-O potential accurately reproduces this basic tetrahedral structure and its dimensions, as well as a fixed-charge model. Regarding MgO RDF (FIG. $2 e \& 2 f$ ), the first peak is asymmetric and never returns to zero, as already stated in previous studies ${ }^{5,33,39}$. This tail is a source of controversy to figure out an adequate $\mathrm{CN}$. Depending on the chosen cutoff distance, this $\mathrm{CN}$ can differ and there is still no consensus on its value. An experimental determination from X-ray diffraction by Wilding et al. ${ }^{33}$ set it at 4.5 in $\mathrm{MgSiO}_{3}$ glass, and at 5.0 in $\mathrm{Mg}_{2} \mathrm{SiO}_{4}$ glass. These values have been calculated by integrating the $\mathrm{T}(\mathrm{r})$ function between the minima on either side of the $\mathrm{Mg}-\mathrm{O}$ peak. In $\mathrm{MD}$, the cutoff is usually fixed at the first minimum of the partial RDF. From our simulation, this minimum is found at $2.87 \AA$ for the $\mathrm{MgSiO}_{3}$ glass, and at $2.85 \AA$ for the $\mathrm{Mg}_{2} \mathrm{SiO}_{4}$ glass. This yields an Mg-O CN equal to 6.0 for both glasses. This MD result is consistent with the experimental value determined by ${ }^{25} \mathrm{Mg}$ 3QMAS NMR ${ }^{40}$ for $\mathrm{x}=0.50$ and by ${ }^{25} \mathrm{Mg}$ NMR spectroscopy ${ }^{41}$ for $0.50<\mathrm{x}<0.67$. This agreement supports the predominance of a distorted octahedral environment for $\mathrm{Mg}$. In order to definitely figure out this $\mathrm{CN}$ issue, if the MD cutoffs are chosen like Wilding et al, as the minima on either side of the MgO peak of the modeled $\mathrm{T}(\mathrm{r})$

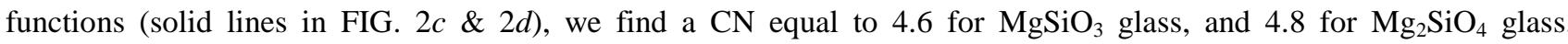
Surprisingly, these MD values are rather close to Wilding et al. experimental ones. Hence, our model is in well agreement with experimental X-ray diffraction and, at the same time, supports the idea of a glass structure in which $\mathrm{Mg}$ are mostly in a distorted octahedral environment. 

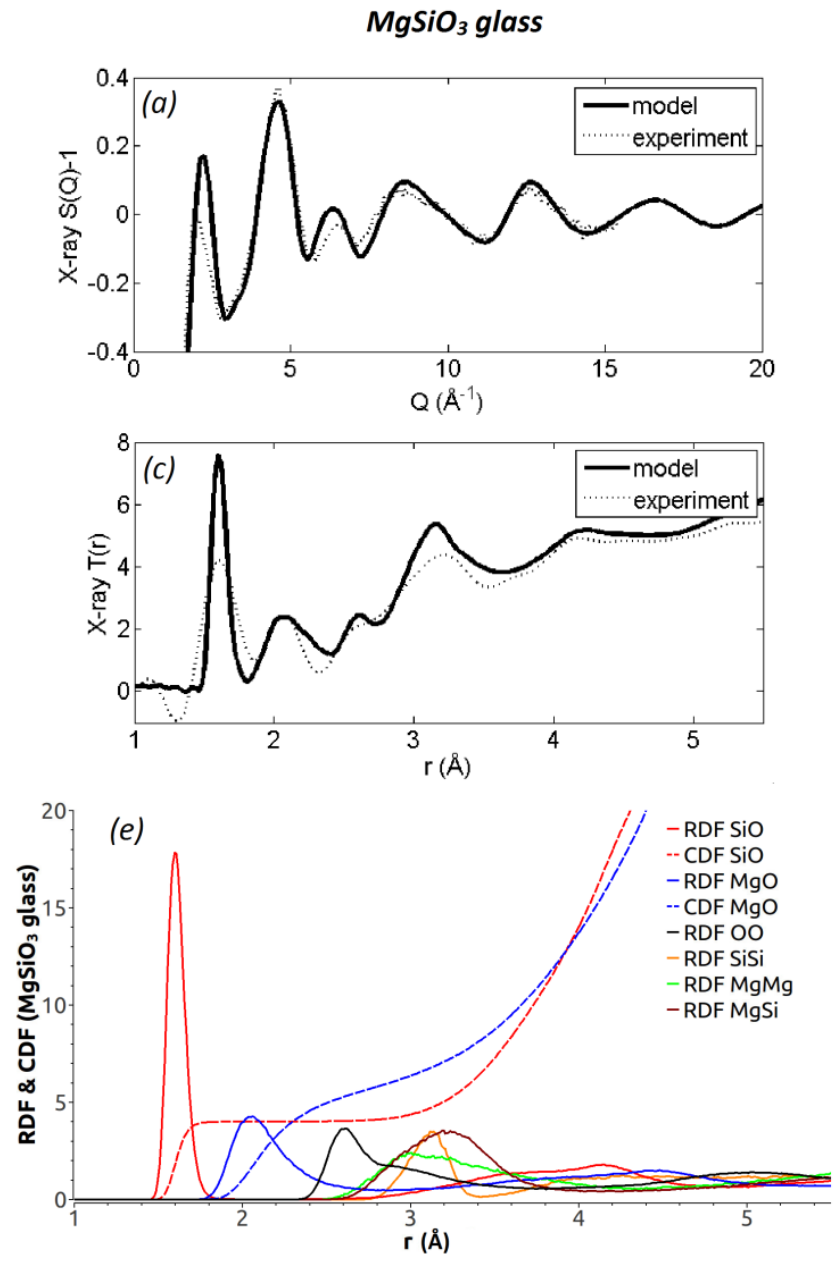

$\mathrm{Mg}_{2} \mathrm{SiO}_{4}$ glass
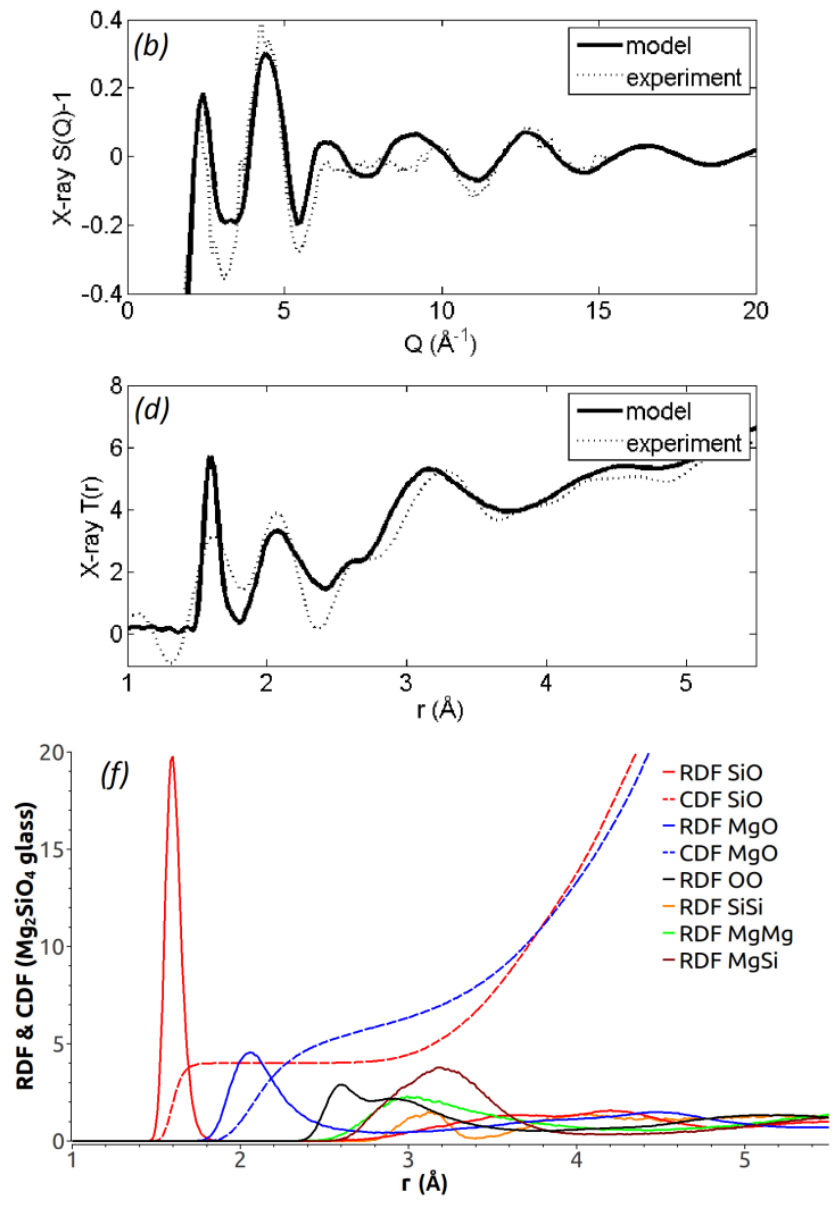

FIG. 2. (Color online) $\mathrm{MgSiO}_{3}$-glass $\mathrm{X}$-ray diffraction: (a) experimental (dotted) and modeled (solid) structure factor $\mathrm{S}(\mathrm{Q})$ ); (c) experimental (dotted) and modeled (solid) total correlation function T(r). $\mathrm{Mg}_{2} \mathrm{SiO}_{4^{-}}$glass $\mathrm{X}$-ray diffraction: (b) experimental (dotted) and modeled (solid) structure factor $\mathrm{S}(\mathrm{Q}) ;(d)$ experimental (dotted) and modeled (solid) total correlation function $\mathrm{T}(\mathrm{r})$. Partial distribution functions of modeled $\mathrm{MgSiO}_{3}$ glass (e) and $\mathrm{Mg}_{2} \mathrm{SiO}_{4}$ glass (f): radial (RDF) and cumulated (CDF).

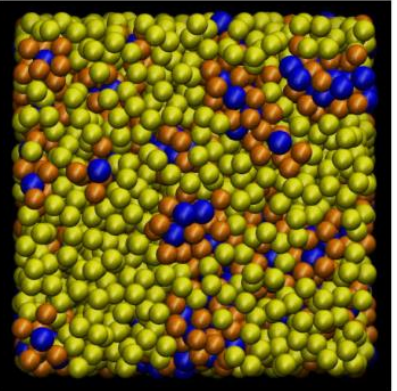

(a) $x=0.1$

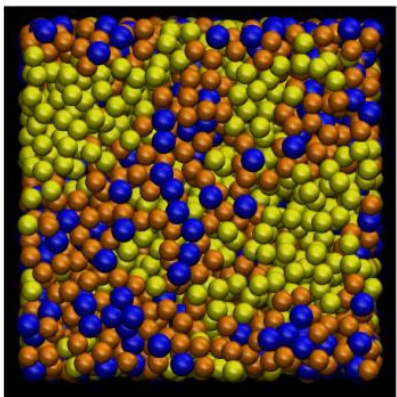

(b) $\quad x=0.2$

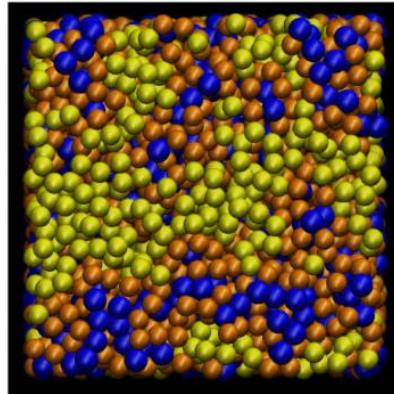

(c) $x=0.3$

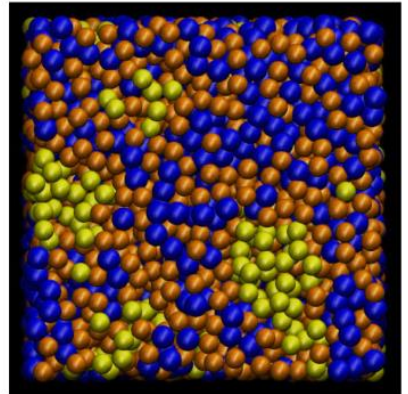

(d) $\quad x=0.4$

FIG. 3. (Color online) 3D renderings of quenched structures of some $\mathrm{xMgO}-(1-\mathrm{x}) \mathrm{SiO}_{2}$ binary glasses. Color code: $\mathrm{Mg}$ atoms (blue), $\mathrm{Si}$ atoms at a distance shorter than $4.0 \AA$ (first minimum of $\mathrm{Mg}$-Si RDF) from $\mathrm{Mg}$ atoms (orange), $\mathrm{Si}$ atoms at a distance longer than 4.0 $\AA$ from $\mathrm{Mg}$ atoms, i.e. demixed $\mathrm{Si}$ atoms (yellow). (a) $\mathrm{x}=0.1$ with 9396 atoms (324 Mg), final box size of $50.31 \AA ;(b) \mathrm{x}=0.2$ with 10206 atoms $(729 \mathrm{Mg})$, final box size of $50.87 \AA ;(c) \mathrm{x}=0.3$ with 11248 atoms $(1250 \mathrm{Mg})$, final box size of $51.80 \AA$; $(d) \mathrm{x}=0.4$ with 12636 atoms $(1944 \mathrm{Mg})$, final box size of $53.03 \AA$.

\section{Phase separation in $\mathrm{xMgO}-(1-\mathrm{x}) \mathrm{SiO}_{2}$ binary glasses}

The proposed reactive potential is efficient to reproduce the properties of the known $\mathrm{MgO}-\mathrm{SiO}_{2}$ systems. Consequently, one can investigate further in studying the phase separation phenomenon which occurs in this binary glass 
as a function of the $\mathrm{MgO}$ fraction. Some 3D renderings of quenched structures are shown in FIG. $3 a, 3 b, 3 c$ and $3 d$, for $\mathrm{xMgO}=0.1,0.2,0.3$ and 0.4, respectively. Demixed phases are, on one hand, Mg-rich Si-poor phases and, on the other hand, Si-rich Mg-poor phases. Regardless of the composition, our MD simulations show that Si atoms are in all phases. This confirms the experimental analysis by Secondary Ion Mass Spectroscopy performed by Blanc et $a{ }^{14}$ on a nanostructured optical fiber composed of, among other compounds, $\mathrm{MgO}$ and $\mathrm{SiO}_{2}$. Their study evidences that $\mathrm{Si}$ atoms are everywhere, in the fiber as well as in nanoparticles, which are thus composed of a mixture of $\mathrm{MgO}$ and $\mathrm{SiO}_{2}$.

TABLE V. Percentage of $\mathrm{Si}$ atoms located at a distance longer than $4.0 \AA$ from $\mathrm{Mg}$ atoms (i.e. demixed $\mathrm{Si}$ atoms) in $\mathrm{xMgO}-(1-$ $\mathrm{x}) \mathrm{SiO}_{2}$ glasses quenched at $0.5 \mathrm{~K} / \mathrm{ps}$, at $5 \mathrm{~K} / \mathrm{ps}$, and in a random distribution with same density than the glass quenched at 0.5 $\mathrm{K} / \mathrm{ps}$.

\begin{tabular}{lccccccccccc}
\hline \hline $\mathrm{xMgO}$ & 0.00 & 0.05 & 0.10 & 0.20 & 0.30 & 0.40 & 0.45 & 0.50 & 0.55 & 0.60 & 0.67 \\
\hline $0.5 \mathrm{~K} / \mathrm{ps}$ & 100.0 & 74.0 & 56.2 & 35.2 & 22.0 & 11.2 & 8.2 & 1.6 & 0.4 & 0.1 & 0.0 \\
\hline $5 \mathrm{~K} / \mathrm{ps}$ & 100.0 & 72.4 & 53.4 & 29.8 & 14.5 & 5.8 & 3.4 & 1.0 & 0.2 & 0.1 & 0.0 \\
\% difference with $0.5 \mathrm{~K} / \mathrm{ps}$ & 0.0 & 1.6 & 2.8 & 5.4 & 7.5 & 5.4 & 4.8 & 0.6 & 0.2 & 0.0 & 0.0 \\
\hline Random distribution & 100.0 & 71.0 & 48.1 & 22.0 & 8.8 & 1.4 & 0.6 & 0.3 & 0.2 & 0.0 & 0.0 \\
\% difference with $0.5 \mathrm{~K} / \mathrm{ps}$ & 0.0 & 3.0 & 8.1 & 13.2 & 13.2 & 9.8 & 7.6 & 1.3 & 0.2 & 0.0 & 0.0 \\
\hline \hline
\end{tabular}

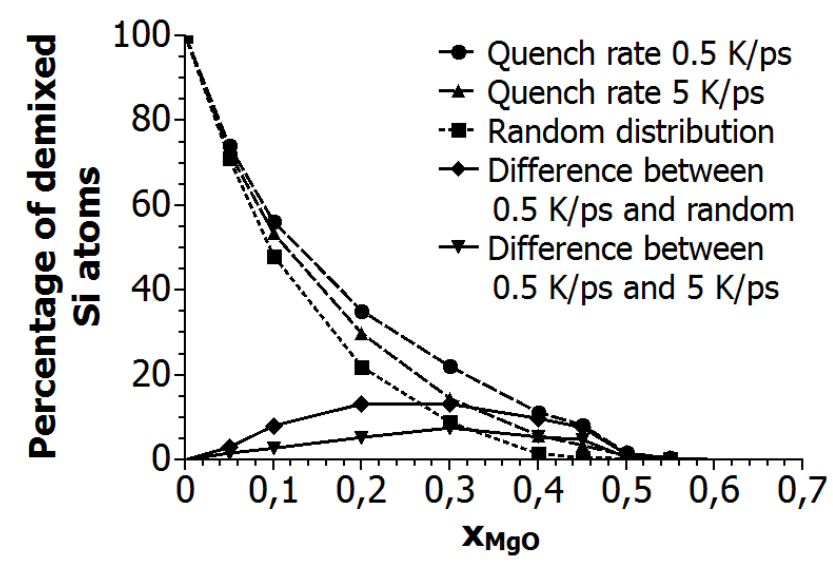

FIG. 4. Percentage of $\mathrm{Si}$ atoms at a distance longer than $4.0 \AA$ from $\mathrm{Mg}$ atoms (i.e. demixed $\mathrm{Si}$ ) in $\mathrm{xMgO}-(1-\mathrm{x}) \mathrm{SiO}_{2}$ binary glasses quenched at $0.5 \mathrm{~K} / \mathrm{ps}$, at $5 \mathrm{~K} / \mathrm{ps}$, and in a random distribution with the same density than the glass quenched at $0.5 \mathrm{~K} / \mathrm{ps}$. "Difference" curves evidence the existence of the phase separation phenomenon and the improvement with a slower quench rate.

TABLE V and FIG. 4 both report, for various compositions and two different quench rates $(0.5 \mathrm{~K} / \mathrm{ps}$ and 5 $\mathrm{K} / \mathrm{ps}$ ), the percentage of $\mathrm{Si}$ atoms located at a distance longer than $4.0 \AA$ (first minimum of Mg-Si RDF - see FIG. 2e \& 2f) from $\mathrm{Mg}$ atoms, i.e. demixed Si atoms. Results for a random distribution with same density than the glass quenched at $0.5 \mathrm{~K} / \mathrm{ps}$ are also presented. The differences with this random distribution (i.e. the higher percentage of demixed $\mathrm{Si}$ atoms) clearly show the existence of the phase separation phenomenon. The quench rate has an effect: it appears that for a slower quench rate, the phase separation is improved. But it occurs only for $\mathrm{xMgO}$ values lower than approximately 0.5. This MD result confirms the large immiscibility gap in this binary glass. Indeed, according to Hageman and Oonk ${ }^{13}$, two liquids can coexist in this system for $\mathrm{xMgO}<0.4$ at the monotectic temperature of $1960 \mathrm{~K}$. In their phase diagram, the top immiscibility boundary forms a dome peaking at $2260 \mathrm{~K}$, temperature beyond of which only one liquid phase can 
exist. In fact, because of the high quench rates in MD, that do not allow any crystallization in this case, this immiscibility dome can be extended below the monotectic temperature and down to the glass transition temperature. This extrapolation leads to a larger immiscibility gap, likely for $\mathrm{xMgO}$ values lower than approximately 0.5 , as evidenced in our $\mathrm{MD}$ simulations.
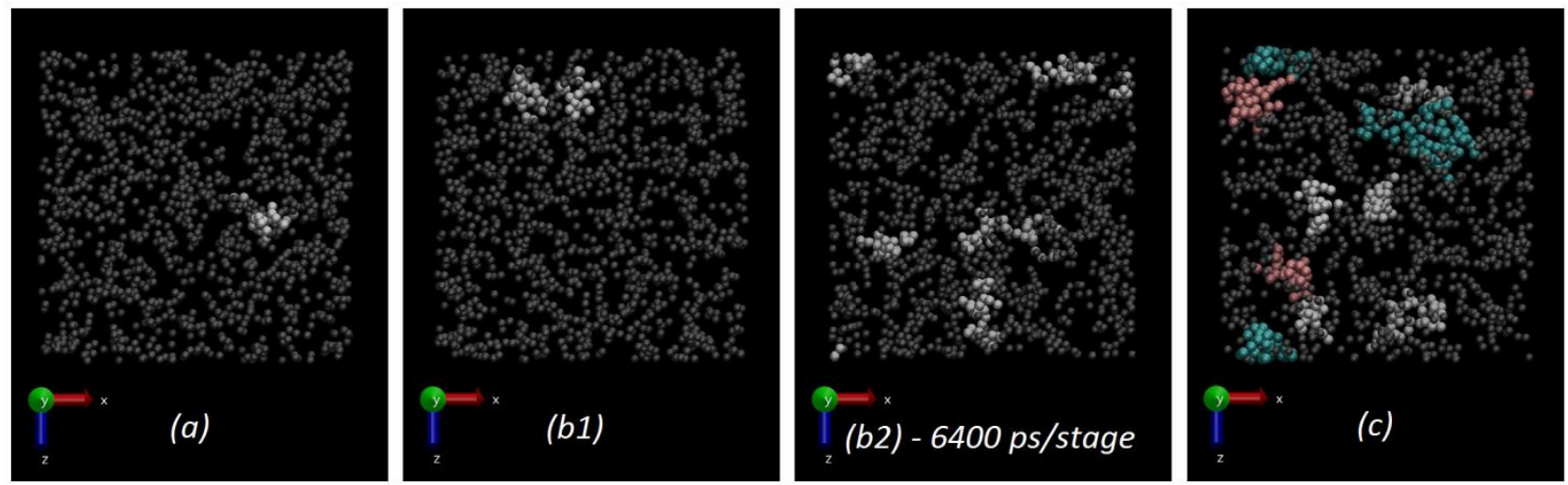

FIG. 5. (Color online) 3D renderings of quenched structures of $0.1 \mathrm{MgO}-0.9 \mathrm{SiO}_{2}$ binary glass. (a) Fixed-charge model from Mountjoy $^{5} ;(b 1)$ and (b2) fixed-charge model from Pedone ${ }^{26} ;(c)$ adaptive potential used here. Only Mg atoms are shown, but a color code is applied to discriminate them according to the size of the phase in which they are located. $\mathrm{Mg}$ atoms separated by less than 4.3 $\AA$ (first minimum of Mg-Mg RDF, for all potentials used here) are considered to belong to the same phase. Color code: see FIG. 6 .
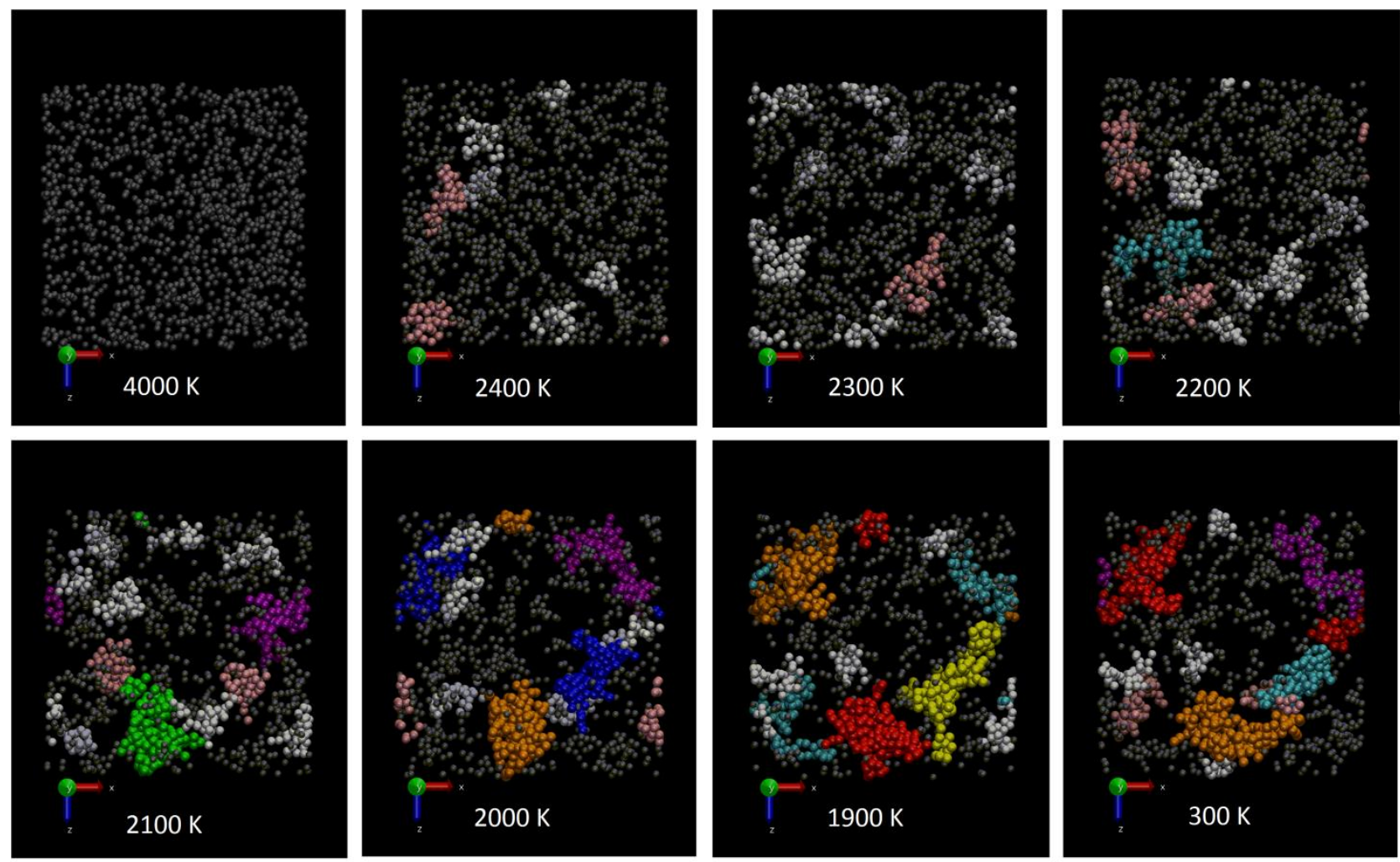

Color code:

\begin{tabular}{|c|c|c|c|c|c|c|c|c|c|c|}
\hline NP color & & & & & & & & & & \\
\hline $\begin{array}{l}\text { Mg atom } \\
\text { content }\end{array}$ & $1-20$ & $21-40$ & $41-60$ & $61-80$ & $81-100$ & $101-120$ & $121-140$ & $141-160$ & $161-180$ & $181-200$ \\
\hline
\end{tabular}

FIG. 6. (Color online) Tracking of the formation of nanoparticles (NP) during the quench of a $0.1 \mathrm{MgO}-0.9 \mathrm{SiO}_{2}$ melt. Only $\mathrm{Mg}$ atoms are shown, but a color code is applied to discriminate them according to the size of the NP in which they are located. Mg atoms separated by less than $4.3 \AA$ (first minimum of the Mg-Mg RDF) are considered to belong to the same NP. 


\section{Formation of nanoparticles (NP) in a $0.1 \mathrm{MgO}-0.9 \mathrm{SiO}_{2}$ glass}

To study the formation of nanoparticles during the phase separation, a melt/quench sequence is performed on a system with an $\mathrm{MgO}$ fraction $\mathrm{x}$ equal to 0.1. The random starting configuration, with a volume of approximately 100x50x100 $\AA^{3}$, contains a total of 37584 atoms $(1296 \mathrm{Mg})$. Before going any further, it is interesting to see how the adaptive model contributes to phase separation when compared to fixed-charge models. The simulation box, with a density set at the extrapolated value of $2.31 \mathrm{~g} / \mathrm{cm}^{3}$ (see FIG. 1), is quenched at $0.5 \mathrm{~K} / \mathrm{ps}$ and at constant volume (NVT), from $4000 \mathrm{~K}$ for our adaptive potential and for Pedone potential ${ }^{26}$ (both with a short-range Morse function), and from $5000 \mathrm{~K}$ for Mountjoy potential ${ }^{5}$ (with a short-range Buckingham function). FIG. $5 a$ (Mountjoy), FIG. $5 b 1$ (Pedone) and FIG. $5 c$ (adaptive potential) display the structures obtained in the same conditions, at the end of the stage at $300 \mathrm{~K}$. Only $\mathrm{Mg}$ atoms are shown ( $\mathrm{Si}$ atoms are everywhere) and a color code is applied to discriminate them according to the size of the phase in which they are located (see FIG. 6 for this color code). Mg atoms separated by less than $4.3 \AA$ (first minimum of Mg-Mg RDF, for all potentials used here) are considered to belong to the same phase. While for fixedcharge models (FIG. $5 a$ \& FIG. 5bl) only 2-4\% of all Mg are involved in phases gathering at least $21 \mathrm{Mg}$, this number rises up to almost $30 \%$ for the adaptive model (FIG. $5 c$ ). To ensure that it is not a matter of the quench that would be too short, a very long simulation described in the next paragraph (with many temperature stages as long as $6400 \mathrm{ps}$ each) is performed, using Pedone potential and the adaptive one. FIG. $5 b 2$ (Pedone) and FIG. 6 at 300K (adaptive) display the structures obtained after this same very long treatment, in the same conditions, at the end of the stage at $300 \mathrm{~K}$. For the fixed-charge model, the comparison of FIG. $5 b 1$ and FIG. $5 b 2$ shows that the improvement induced by this quench 16 times slower is low: $10 \%$ of all $\mathrm{Mg}$ are involved in phases gathering at least $21 \mathrm{Mg}$, whereas it is $57 \%$ with the adaptive model (FIG. 6 at 300K). Consequently, taking into account the different ionicity of metal-Oxygen bonds and the ability for Oxygen atom to react to its environment are both key features to reproduce the separation of $\mathrm{Mg}$-rich $\mathrm{Si}$-poor phases from Mg-poor Si-rich ones.

To form larger separated phases, the random starting configuration is now quenched at $0.5 \mathrm{~K} / \mathrm{ps}$ from $4000 \mathrm{~K}$ to $2400 \mathrm{~K}$. Then, very long stages of 6400 ps are successively performed at $2300 \mathrm{~K}, 2200 \mathrm{~K}, 2100 \mathrm{~K}, 2000 \mathrm{~K}$ and $1900 \mathrm{~K}$. Such a long time is assigned to these stages between $2400 \mathrm{~K}$ and $1900 \mathrm{~K}$ because it has been noticed that the phase separation occurs within this temperature range for this composition. Above $2400 \mathrm{~K}$, there is only one fluctuating liquid. Below $1900 \mathrm{~K}$, which is more than $300 \mathrm{~K}$ below the glass-transition temperature $\mathrm{T}_{\mathrm{g}}$, the structure is practically fixed $\left(\mathrm{T}_{\mathrm{g}}\right.$ $=2196 \pm 10 \mathrm{~K}$ for this system quenched at $1 \mathrm{~K} / \mathrm{ps}$ ). Times longer than $6400 \mathrm{ps}$ have been tested, but with no improvement for this box size. Finally, the system is quenched from $1900 \mathrm{~K}$ at $0.5 \mathrm{~K} / \mathrm{ps}$ to get the ultimate structure at $300 \mathrm{~K}$. The nanoparticle formation is tracked by means of successive 3D renderings. The FIG. 6 displays the structures obtained at the end of each stage within the temperature range of interest (at $4000 \mathrm{~K}$, from $2400 \mathrm{~K}$ to $1900 \mathrm{~K}$, and at $300 \mathrm{~K}$ ). Again, 
only $\mathrm{Mg}$ atoms are shown ( $\mathrm{Si}$ atoms are everywhere, even in $\mathrm{NP}$ ) and a color code is applied to discriminate them according to the size of the NP in which they are located. Mg atoms separated by less than $4.3 \AA$ (first minimum of the Mg-Mg RDF) are considered to belong to the same NP.

At the end of the stage at $4000 \mathrm{~K}$, the liquid is homogeneous: no phase separation is observed. At the end of this simulation, the two largest NP (the red and the orange ones in FIG. 6 at $300 \mathrm{~K}$ ) are not spherical, and their longest dimensions are $66 \AA$ and $49 \AA$, respectively. A non-spherical shape in related cases can be found in the experimental studies by Atom Probe Tomography of Silicon $\mathrm{NP}^{42}$ or Erbium-rich clusters ${ }^{43}$ in $\mathrm{SiO}_{2}$. Our two largest NP contain 188 and $164 \mathrm{Mg}$ atoms, respectively. This represents $14.5 \%$ and $12.7 \%$ of the total number of $\mathrm{Mg}$ atoms, respectively, as shown in the FIG. 7 representing the evolution of the NP size distribution during the quench. As the temperature decreases, less and less Mg atoms are involved in small NP, to form NP becoming larger and larger. All formed NP remain amorphous.

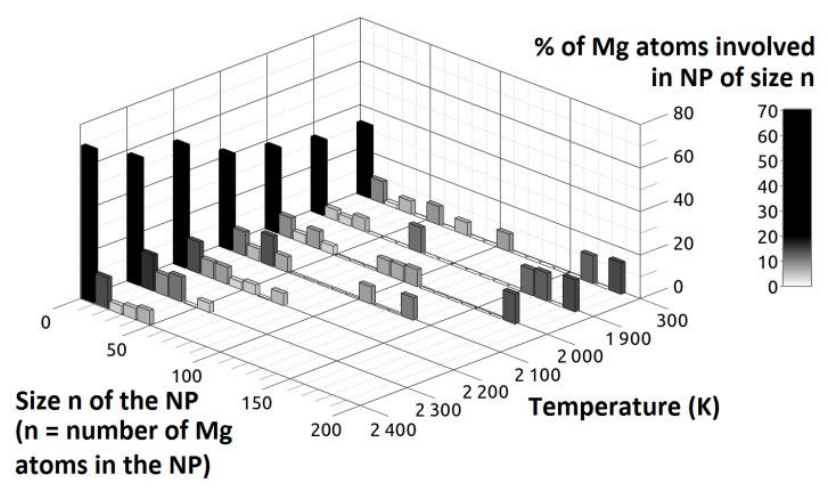

FIG. 7. Evolution of NP size distribution during the quench of a $0.1 \mathrm{MgO}-0.9 \mathrm{SiO}_{2}$ binary melt.

The FIG. 8 represents the partial charge distribution of Oxygen atoms present in this demixed glass. This distribution can be reconstructed by a sum of two Gaussian functions, with a correlation coefficient $R^{2}=0.9991$, very close to 1 . The first Gaussian is centered on -1.2029e, which is the mean charge of Oxygen atoms in the Si-rich Mg-poor phase. Since this value is simply linked to the $\mathrm{MgO}$ fraction, we can determine that this phase contains $4.4 \pm 0.9 \% \mathrm{~mol}$ $\mathrm{MgO}$. The second Gaussian is centered on -1.2204e, which is the mean charge of Oxygen atoms in all the Mg-rich Sipoor phases, i.e. combining all NP. In the same way, we can determine that these phases contain an average of $27 \pm 4$ $\% \mathrm{~mol} \mathrm{MgO}$. This short analysis confirms once more the experimental trend for the composition of these Mg-rich Si-poor nanoparticles ${ }^{14,15}$, which finally contain a large amount of Si atoms. Scaled to the total number of atoms $(\mathrm{Mg}, \mathrm{Si}$ and $\mathrm{O})$, this Mg proportion in overall modeled NP represents 9.9\%at, and 1.5\% at in the matrix. 


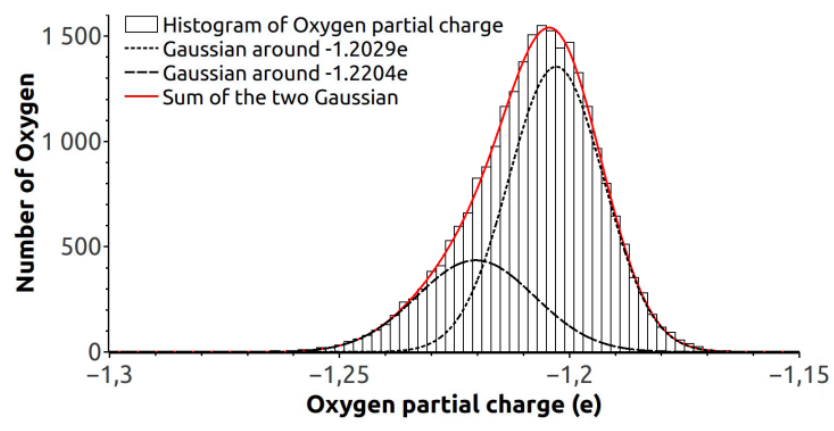

FIG. 8. Distribution of Oxygen partial charge in a demixed $0.1 \mathrm{MgO}-0.9 \mathrm{SiO}_{2}$ binary glass.

The difference of Oxygen charge between the Si-rich phase and Mg-rich ones is tiny (less than $1.5 \%$ ). As a reminder, in comparison to Pedone fixed-charge model, the Magnesium charge has been enhanced by only $10 \%$ in order to take into account the more ionic character of $\mathrm{Mg}-\mathrm{O}$ bond. These small modifications finally become necessary to induce the phase separation occurring in this binary system. Many examples of such a subtle balance between molecular interactions yielding a phase separation can be found in literature, in modeled as well as real physical systems. For instance, in the theoretical study of Lennard-Jones liquid mixtures ${ }^{44}$, a slight alteration of the Lorentz-Berthelot combining rules completely changes the mixing behavior. This has been used to improve the qualitative agreement with experiment of water-alcohol mixtures ${ }^{45}$. In real physical systems, a simple deuteration of organic molecules has an effect on their miscibility ${ }^{46}$.

\section{v. CONCLUSIONS}

The main feature of the potential developed in this paper is to take into account the more or less covalent character of metal-Oxygen bonds in bulk ionic materials. A unique set of parameters is enough to explore the full composition range of the $\mathrm{MgO}-\mathrm{SiO}_{2}$ system. Cations are assumed to have a fixed charge. The global and local transferability is assured by the ability for each Oxygen ion to adapt its partial charge according to its own local cationic environment. When compared to fixed-charge models, this simple adaptive potential is far more efficient to reproduce the phase separation phenomenon in the $\mathrm{MgO}-\mathrm{SiO}_{2}$ binary system, as predicted by the phase diagram ${ }^{13}$ and as experimentally observed with the formation of nanoparticles (NP) ${ }^{14,15}$. Indeed, this is the first time, using Molecular Dynamics technique, that such large NP are formed in this system, with a composition trend in agreement with the known experimental data. This method can easily be transposed to other binary or ternary systems, or more complex ionic bulk materials. It allows the modeling of much larger systems, for instance to study the formation of doped NP with 
a very low amount of rare-earth ions. Moreover, the effects of the usual heat treatments on the nucleation/growth process of these NP could be investigated more deeply, and would deserve a whole study.

\section{ACKNOWLEDGEMENT}

This work was supported by grant from Région Pays de la Loire (NACRYSIM program). This research used resources of the CCIPL (Centre de Calcul Intensif des Pays de Loire). We are grateful to Gavin Mountjoy for useful discussions. Authors want to thank the reviewers for constructive comments and suggestions.

${ }^{1}$ P. Hudon and D.R. Baker, J. Non-Cryst. Solids 303, 299 (2002).

${ }^{2}$ S. Amore, J. Horbach, and I. Egry, J. Chem. Phys. 134, 044515 (2011).

${ }^{3}$ S. Sarkar and B. Bagchi, Phys. Rev. E 83, 031506 (2011).

${ }^{4}$ R.N. Mead and G. Mountjoy, J. Phys. Chem. B 110, 14273 (2006).

${ }^{5}$ B.M. Al-Hasni and G. Mountjoy, J. Non-Cryst. Solids 400, 33 (2014).

${ }^{6}$ U. Voigt, H. Lammert, H. Eckert, and A. Heuer, Phys. Rev. B 72, 064207 (2005).

${ }^{7}$ J. Du and A.N. Cormack, J. Non-Cryst. Solids 351, 2263 (2005).

${ }^{8}$ N.D. Afify and G. Mountjoy, Phys. Rev. B 79, 024202 (2009).

${ }^{9}$ C. Huang and A.N. Cormack, J. Chem. Phys. 95, 3634 (1991).

${ }^{10}$ G.N. Greaves, J. Non-Cryst. Solids 71, 203 (1985).

${ }^{11}$ P. Chieux, J. Mol. Struct. 296, 177 (1993).

${ }^{12}$ M.C. Davis, K.J. Sanders, P.J. Grandinetti, S.J. Gaudio, and S. Sen, J. Non-Cryst. Solids 357, 2787 (2011).

${ }^{13}$ V.B.M. Hageman and H. a. J. Oonk, Phys. Chem. Glas. 27, 194 (1986).

${ }^{14}$ W. Blanc, C. Guillermier, and B. Dussardier, Opt. Mater. Express 2, 1504 (2012).

${ }^{15}$ H. Francois-Saint-Cyr, I. Martin, W. Blanc, P. LeCoustumer, C. Hombourger, D. Neuville, D.J. Larson, T.J. Prosa, and C. Guillermier, Microsc. Microanal. 20, 994 (2014).

${ }^{16}$ A.C.T. van Duin, A. Strachan, S. Stewman, Q. Zhang, X. Xu, and W.A. Goddard, J. Phys. Chem. A 107, 3803 (2003).

${ }^{17}$ T.-R. Shan, B.D. Devine, J.M. Hawkins, A. Asthagiri, S.R. Phillpot, and S.B. Sinnott, Phys. Rev. B 82, 235302 (2010).

${ }^{18}$ L.-H. Kieu, J.-M. Delaye, L. Cormier, and C. Stolz, J. Non-Cryst. Solids 357, 3313 (2011).

${ }^{19}$ L. Huang and J. Kieffer, Phys. Rev. B 74, 224107 (2006).

${ }^{20}$ P. Beck, P. Brommer, J. Roth, and H.-R. Trebin, J. Chem. Phys. 135, 234512 (2011).

${ }^{21}$ G. Pacchioni and F. Illas, Chem. Phys. 199, 155 (1995). 
${ }^{22}$ U. Birkenheuer, J.C. Boettger, and N. Rösch, J. Chem. Phys. 100, 6826 (1994).

${ }^{23}$ A.K. Rappe and W.A. Goddard III, J. Phys. Chem. 95, 3358 (1991).

${ }^{24}$ J.D. Gale, J. Chem. Soc. Faraday Trans. 93, 629 (1997).

25 J.D. Gale and A.L. Rohl, Mol. Simul. 29, 291 (2003).

${ }^{26}$ A. Pedone, G. Malavasi, M.C. Menziani, A.N. Cormack, and U. Segre, J. Phys. Chem. B 110, 11780 (2006).

${ }^{27}$ S. Plimpton, J. Comput. Phys. 117, 1 (1995).

${ }^{28}$ D. Wolf, P. Keblinski, S.R. Phillpot, and J. Eggebrecht, J. Chem. Phys. 110, 8254 (1999).

${ }^{29}$ A. Carré, L. Berthier, J. Horbach, S. Ispas, and W. Kob, J. Chem. Phys. 127, 114512 (2007).

${ }^{30}$ P. Brommer, P. Beck, A. Chatzopoulos, F. Gähler, J. Roth, and H.-R. Trebin, J. Chem. Phys. 132, 194109 (2010).

${ }^{31}$ P. Demontis, S. Spanu, and G.B. Suffritti, J. Chem. Phys. 114, 7980 (2001).

${ }^{32}$ C.J. Fennell and J.D. Gezelter, J. Chem. Phys. 124, 234104 (2006).

${ }^{33}$ M.C. Wilding, C.J. Benmore, J.A. Tangeman, and S. Sampath, Chem. Geol. 213, 281 (2004).

${ }^{34}$ R. Brückner, J. Non-Cryst. Solids 5, 123 (1970).

35 J.E. Shelby, J. Non-Cryst. Solids 349, 331 (2004).

${ }^{36}$ K. Vollmayr, W. Kob, and K. Binder, Phys. Rev. B 54, 15808 (1996).

${ }^{37}$ T. Hanada, N. Soga, and T. Tachibana, J. Non-Cryst. Solids 105, 39 (1988).

${ }^{38}$ G. Mountjoy, B.M. Al-Hasni, and C. Storey, J. Non-Cryst. Solids 357, 2522 (2011).

${ }^{39}$ M. Guignard and L. Cormier, Chem. Geol. 256, 111 (2008).

${ }^{40}$ K. Shimoda, Y. Tobu, M. Hatakeyama, T. Nemoto, and K. Saito, Am. Mineral. 92, 695 (2007).

${ }^{41}$ S. Sen, H. Maekawa, and G.N. Papatheodorou, J. Phys. Chem. B 113, 15243 (2009).

${ }^{42}$ E. Talbot, R. Lardé, F. Gourbilleau, C. Dufour, and P. Pareige, EPL Europhys. Lett. 87, 26004 (2009).

${ }^{43}$ E. Talbot, R. Lardé, P. Pareige, L. Khomenkova, K. Hijazi, and F. Gourbilleau, Nanoscale Res. Lett. 8, 1 (2013).

${ }^{44}$ M. Rouha and I. Nezbeda, Fluid Phase Equilibria 277, 42 (2009).

${ }^{45}$ F. Moučka and I. Nezbeda, J. Mol. Liq. 159, 47 (2011).

${ }^{46}$ H. Yang, M. Shibayama, R.S. Stein, N. Shimizu, and T. Hashimoto, Macromolecules 19, 1667 (1986). 